УДК 664

\title{
АВТОМАТИЗИРОВАННОЕ ПРОЕКТИРОВАНИЕ РЕЦЕПТУР ПОЛИФУНКЦИОНАЛЬНЫХ РЫБНЫХ ПИЩЕВЫХ ПРОДУКТОВ, ОБОГАЩЕННЫХ ЦЕННЫМИ КОМПОНЕНТАМИ, ИЗ МАЛОИСПОЛЬЗУЕМОГО РЫБНОГО СЫРЬЯ СЕВЕРНОГО БАССЕЙНА
}

\author{
Новожилова Елена Андреевна \\ аспирант
}

Тациенко Екатерина Андреевна аспирант

Савкина Ксения Николаевна аспирант

\section{Павлова Валентина Владимировна}

заведующая лабораторией кафедры технологий пищевых производств Научный руководитель: Шокина Юлия Валерьевна д.т.н., профессор ФГАОУ ВО «Мурманский государственный технический университет»

\begin{abstract}
Аннотация: разработаны оптимальные рецептуры ассортимента полифункциональных рыбных продуктов, обогащенных ценными пищевыми компонентами - хондроитинсульфатом ската звездчатого и йодом в составе сушеной ламинарии. При разработке рецептур использован современный математический аппарат - метод нечеткой логики в программном пакете MatLab. Выполненая экспериментальная проверка оптимальных рецептур подтвердила хорошую сходимость результатов математического моделирования с реальным технологическим процессом. Все разработанные продукты удовлетворяют требованиям ГОСТ Р 52349-2005 «Продукты пищевые. Продукты пищевые функциональные. Термины и определения» и ГОСТ Р 55577-2013 «Продукты пищевые специализированные и функциональные. Информация об отличительных признаках и эффективности».

Ключевые слова: продукты рыбные пищевые полифункциональные и обогащенные, хондроитинсульфат, йод
\end{abstract}




\title{
AUTOMATED RECIPE DESIGN MULTIFUNCTIONAL FISH FOOD PRODUCTS, ENRICHED WITH VALUABLE COMPONENTS, FROM LITTLE-USED FISH RAW MATERIALS NORTHERN BASIN
}

\author{
Novozhylova Elena Andreevna \\ Tazcienko Ekaterina Andreevna \\ Savkina Ksenya Nikolaevna \\ Pavlova Valentina Vladimirovna \\ Scientific adviser: Shokina Yulia Valerievna
}

\begin{abstract}
: optimal recipes of the assortment of multifunctional fish products enriched with valuable food components - chondroitin sulfate of stingray and iodine in the composition of dried kelp have been developed. When developing recipes, a modern mathematical apparatus was used - the method of fuzzy logic in the MatLab software package. The experimental verification of optimal formulations confirmed the good convergence of the results of mathematical modeling with the real technological process. All developed products meet the requirements of State Agricultural Standard of Russian Federation 52349-2005 " Food products. Functional food products. Terms and definitions" and State Agricultural Standard of Russian Federation 55577-2013 " Specialized and functional food products. Information about distinctive features and effectiveness".
\end{abstract}

Key words: multifunctional and enriched fish food products, chondroitin sulfate, iodine

Несбалансированное питание современного человека, по единогласному мнению специалистов, - основная причина возникновения сердечнососудистых заболеваний, сахарного диабета, подагры, остеопароза и ожирения, гипо- и гипертиреоза и многих других неинфекционных социально значимых заболеваний. Несбалансированное питание как фактор риска развития заболеваний и снижения трудоспособности и качества жизни населения Российской Федерации обусловливает актуальность проблемы обеспеченности продуктами питания массового потребления, обладающими повышенной пищевой и биологической ценностью за счет сбалансированного по микронутриентам и биологически активным веществам состава. Расширение ассортимента функциональных, обогащенных продуктов и продуктов специализированного питания, направленных на системную профилактику 


\section{ПЕРСПЕКТИВНЫЕ РАЗРАБОТКИ ПО ПРИОРИТЕТНЫМ НАПРАВЛЕНИЯМ РАЗВИТИЯ}

вышеуказанных заболеваний и повышение качества жизни россиян, является главным приоритетом национальных программ развития пищевой и перерабатывающей отраслей.

Еще одной важной тенденцией, характеризующей жизнь современного человека, является ее высокий темп, неуклонно растущий все последнее десятилетие, как и занятость россиян. Сочетание этих факторов формирует устойчивый повышенный спрос на полностью готовые к употреблению или требующие минимальной доготовки продукты питания.

Исследованиями специалистов-маркетологов установлено, что в 2020 году более половины всех продуктов питания, приобретаемых российскими потребителями в розничной торговой сети, принадлежали к указанным категориям [2]. В настоящее время большинство авторитетных маркетинговых агентств, участвующих в формировании бизнес-планов отечественных пищевых и перерабатывающих производств, считает наиболее перспективным развитие производства продуктов в категории «ready to eat», «ready to cook» в сочетании с реализацией основной доли продуктов через сеть интеренет.

Проведенное исследование потребительских предпочтений россиян в отношении рыбных кулинарных продуктов показало, что до 77 \% респондентов предпочитают продукты отечественного производства [2].

Как известно, бурые водоросли, в частности Laminaria saccharina или морская капуста содержат значительное количество, так называемого органического йода, благодаря чему могут широко применяться в технологиях обогащенных продуктов питания, направленных на профилактику йододефицитных состояний. Органический йод, присутствующий в составе ламинарии обладает высокой биодоступностью для организма человека и практически не вызывает нежелательных аллергических реакций в оптимальных дозировках, не превышающих физиологическую норму суточного потребления, установленную в российской Федерации (не более 150 мкг в сутки для взрослого человека).

В Мурманском государственном техническом университете в течение последнего десятилетия ведутся разработки технологий рыбных продуктов, обогащенных хондроитинсульфатом ската звездчатого - хрящевой рыбы, которая составляет основу прилова при промышленной добыче тресковых рыб. Хондроитинсульфат обладает научно доказанной эффективностью в комплексной терапии воспалительных заболеваний костной и хрящевой ткани 


\section{ПЕРСПЕКТИВНЫЕ РАЗРАБОТКИ ПО ПРИОРИТЕТНЫМ НАПРАВЛЕНИЯМ РАЗВИТИЯ}

человека, а также обладает ангиопротекторным действием, вследствие чего входит в состав многих весьма дорогостоящих лекарственных препаратов и БАД в количестве 250 и 500 мг на однократный прием. Между тем мурманскими учеными доказано содержание хондроитинсульфата в рыбных кулинарных продуктах, в составе которых представлена мышечная и хрящевая ткань крыльев ската звездчатого от 220 до 280 мг на 100 г продукта.

С учетом вышеизложенного разработка технологий рыбных продуктов категорий «ready to cook» и «ready to eat», в том числе обогащенных ценными компонентами - йодом в составе бурой водоросли Laminaria saccharina и хондроитинсульфатом в составе мышечной и хрящевой ткани крыльев ската звездчатого представляет собой актуальную цель исследования.

Алгоритм разработки новых обогащенных рыбных продуктов представляет собой несколько последовательных этапов: маркетинговое исследование для оценки потребительского рынка и выявления потребительских предпочтений в отношении исследуемой группы продуктов с обоснованием выбора вида нового продукта $\rightarrow$ выбор базовой (существующей) технологии рыбного продукта и основного рыбного сырья $\rightarrow$ выбор обогащающей добавки или пищевого ингредиента / сырья, содержащего ингредиент в больших количествах, и определение их необходимого содержания в готовом продукте для обеспечения статуса «обогащенный продукт» $\rightarrow$ автоматизированное проектирование рецептуры с использованием современных математических методов $\rightarrow$ проверка оптимальной рецептуры путем изготовления опытных партий нового продукта и корректировка (при необходимости технологи изготовления $\rightarrow$ установление или подтверждение сроков годности нового продукта $\rightarrow$ разработка технической документации на новый продукт.

По вышеприведенному алгоритму в настоящее время спроектированы автоматизированным способом рецептуры нескольких рыбных продуктов с использованием зубатки синей и ската звездчатого, результаты исследований представлены ниже.

Зубатка синяя (Anarhichas denticulatu) широко распространена по всей акватории Баренцева моря, ее вылов не лимитируется величиной общего допустимого улова (ОДУ), при этом промысловые запасы делают возможным и целесообразным специализированный промысел. По данным ученых Полярного филиала ФГБНУ «ВНИРО» («ПИНРО» им. Н.М. Книповича) в 2019 году вылов зубатки синей составил 75,7 \% от величины рекомендуемого объёма 


\section{ПЕРСПЕКТИВНЫЕ РАЗРАБОТКИ ПО ПРИОРИТЕТНЫМ НАПРАВЛЕНИЯМ РАЗВИТИЯ}

улова, или в натуральном выражении 15,969 тыс. тонн рыбы. Таким образом, налицо значительный и недоиспользуемый в промышленной переработке сырьевой ресурс для новых рыбных продуктов категории «ready to eat».

В качестве базовых технологий для продуктов из зубатки синей с учетом результатов изучения рынка и потребительских предпочтений выбраны технологии рыбного суфле, фишпика и хлебцев итальянских с сыром и базиликом. В качестве обогащающей добавки выбрана сушеная ламинария с содержанием йода около 50 \% на сухое вещество.

Для исследований использовали сушеную дикую морскую капусту производства Архангельского водорослевого комбината и объект марикулььтуры - ламинарию холодной сушки производства норвежской компании «Energy Solutions AS» [3,c. 82-84], которую подвергали тонкому измельчению до порошкообразного состояния, после чего вносили в рецептурный сырьевой набор.

Для изготовления суфле отварное мясо зубатки и припущенную морковь тонко измельчали, соединяли в пропорции, согласно разработанной рецептуре, в полученную смесь добавляли соль, пряности и тонко измельченную ламинарию. Смесь еще раз подвергали тщательному перемешиванию после чего вводили взбитые яичные белки и снова аккуратно перемешивали. Готовую для термической обработки смесь расфасовывали в потребительскую тару и доводили до кулинарной готовности обработкой паром, после чего охлаждали до температуры от 2 до $6{ }^{\circ} \mathrm{C}$ и хранили при той же температуре. Перед употреблением продукт рекомендуется разогреть в микроволновой печи или на водяной бане в зависимости от использованной потребительской упаковки.

Для изготовления фишпика термически обработанное мясо зубатки, творожный сыр, термически обработанные овощи (перец красный сладкий, морковь), чеснок, хрен, зелень, специи смешивали в пропорции, согласно разработанной рецептуре, и измельчали до однородной массы, гомогенизировали, после чего готовый продукт расфасовывали в потребительскую тару (алюминиевые тубы) и хранили в охлажденном виде при температуре от 2 до $6^{\circ} \mathrm{C}$.

Оптимизацию рецептур указанных продуктов осуществляли в программе Fuzzy Logic Toolbox пакета MatLab методом нечеткого логического вывода. Параметром оптимизации (выходной переменной) являлась органолептическая оценка готового продукта в баллах по разработанной пятибалльной шкале. В качестве влияющих факторов (входных переменных) выбраны компоненты 
рецептуры, ключевым образом формирующие органолептическую оценку готового продукта.

Доля сушеной ламинарии, добавляемой в рецептурный набор, исключена из влияющих факторов и не подвергалась варьированию в ходе экспериментов, поскольку содержание йода в готовом продукте строго ограничено требованиями ГОСТ Р 52349-2005 «Продукты пищевые. Продукты пищевые функциональные. Термины и определения» и ГОСТ Р 55577-2013 «Продукты пищевые специализированные и функциональные. Информация об отличительных признаках и эффективности» и установленным экспериментально содержанием йода в используемой для обогащения сушеной ламинарии. Доля добавляемой сушеной ламинарии была рассчитана с учетом достижения в готовом продукте массовой доли йода от 22,5 до 75 мкг на 100 г продукта (соответствует от 15 до $50 \%$ суточной физиологической нормы потребления йода в РФ) и поддерживалась постоянной во всей серии экспериментов. Таким образом, варьированию подвергались исключительно факторы, влияющие наиболее существенным образом на итоговую органолептическую оценку готовой продукта.

Для суфле входные переменные - яичный белок, морковь припущенная и овсяная мука, используемая в качестве загустителя в процентах на общую массу полуфабриката до финальной тепловой обработки паром. Для фишпика входные переменные - бланшированное в воде мясо зубатки и чеснок свежий в процентах от массы нетто полуфабриката до измельчения и гомогенизации.

По результатам предварительных экспериментов были ограничены области факторного пространства и приняты лингвистические термы для всех переменных. Составленная матрица эксперимента использовалась для изготовления опытных образцов продукции и формулирования правил (базы данных). Органолептическая оценка всех опытных образцов продукции проводилась путём расширенной дегустации специалистами. В программе «Fuzzy logic» пакета MatLab смоделирована рецептура продуктов с наивысшей органолептической оценкой. Результаты моделирования в виде поверхности отклика представлены на рис. 1 и 2.

Определены оптимальные значения входных переменных для разрабатываемых рецептур обогащенных продуктов, которые составили:

- для суфле - яичный белок - 20,5, морковь припущенная - 20,2, мука овсяная - 5,0 процентов на общую массу полуфабриката до финальной тепловой обработки паром; 
- для фишпика - мясо зубатки - 61, чеснок свежий - 0,95 процентов от массы нетто сырьевого набора до измельчения и гомогенизации.

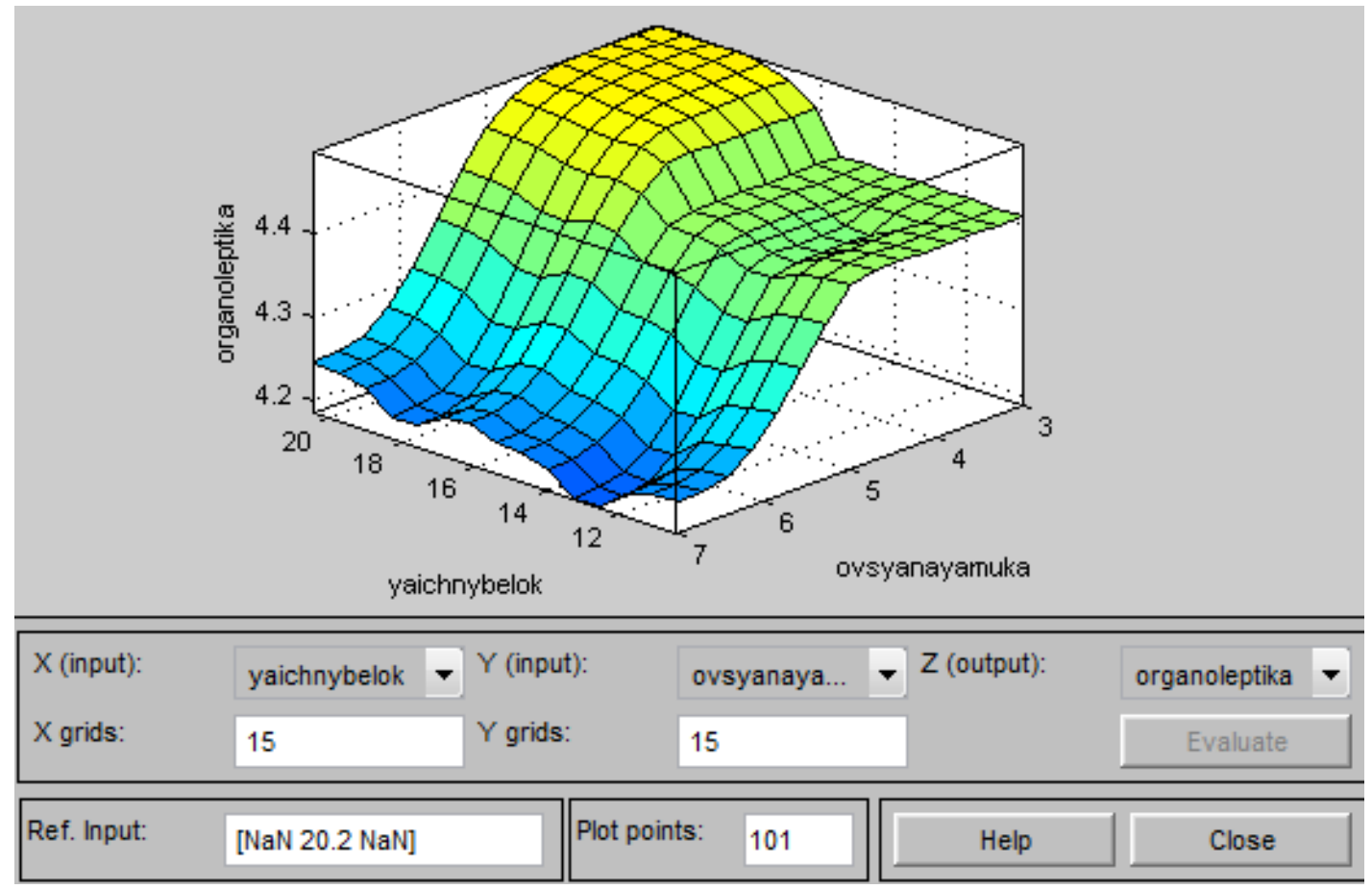

Рис. 1. Поверхность отклика для продукта «Суфле из зубатки синей с морковью, обогащенное йодом»

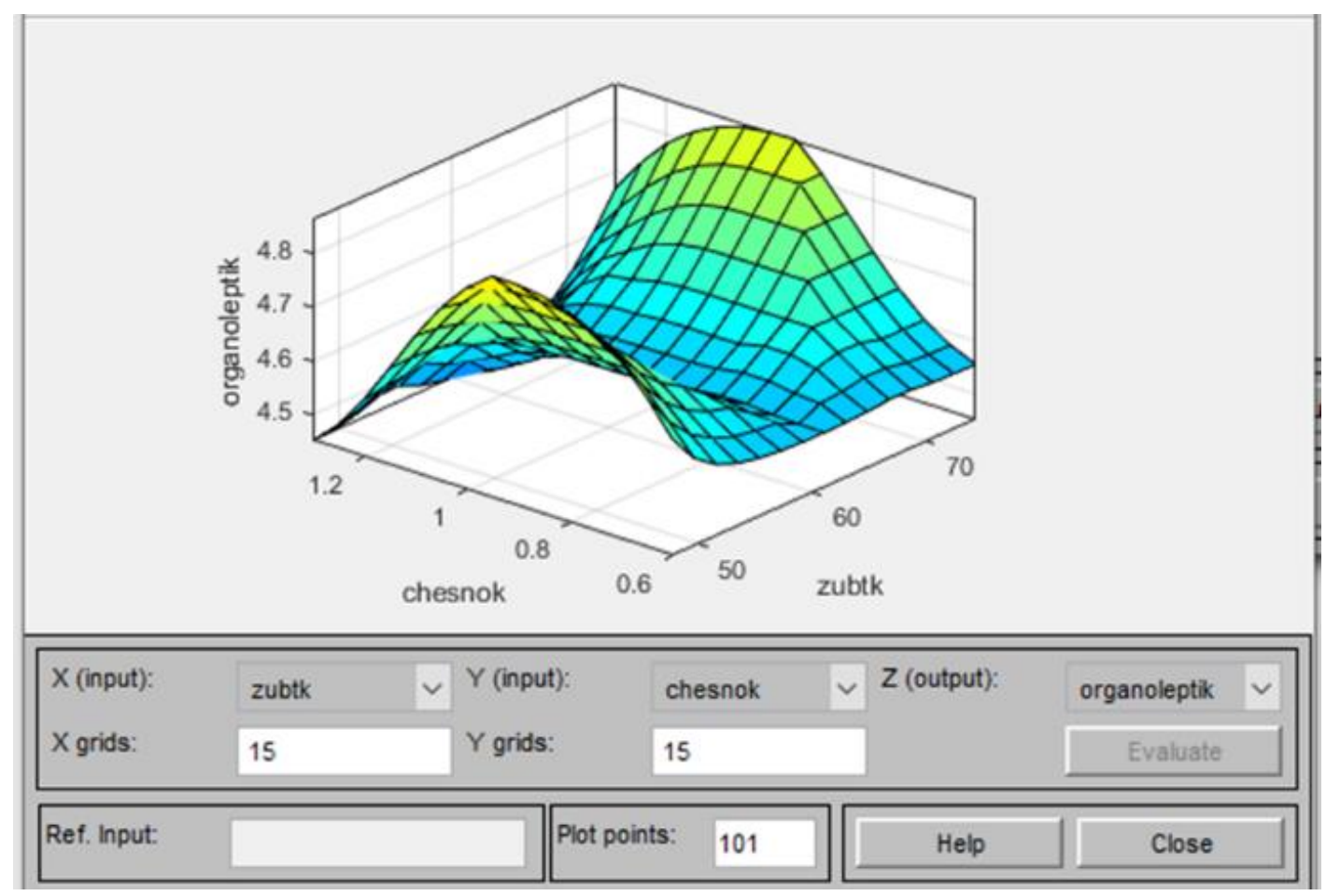

Рис. 2. Поверхность отклика для продукта «Фишпик из синей зубатки с овощами, обогащённый йодом» 
Полученные оптимальные значения факторов проверены экспериментально, показали хорошую сходимость и учтены в конечной рецептуре разработанных продуктов и проектной технической документации ТУ «Продукция кулинарная из зубатки синей, обогащенная йодом». Оптимизацию рецептуры нового мучного изделия «Хлебцы итальянские, обогащенные йодом» проводили, как и в случае с продуктами из зубатки синей по критерию достижения максимальной органолептической оценки готовым продуктом.

Для изготовления хлебцев муку пшеничную цельнозерновую, муку ржаную соединяли с солью, медом, тертыми бланшированными томатами, освобожденными от кожицы, тертым сыром пармезан и сушеными базиликом и ламинарией, после чего замешивали крутое тесто, охлаждали в течение 30 минут при температуре от 4 до $8{ }^{\circ} \mathrm{C}$. Готовое тесто раскатывали, нарезали по форме тестовые заготовки хлебцев и выпекали их при температуре от 140 до $160{ }^{\circ} \mathrm{C}$ в течение 20 - 40 минут. Готовые хлебцы охлаждали до температуры не выше $18{ }^{\circ} \mathrm{C}$, расфасовывали в потребительскую тару (ламинированные картонные коробки, полипакеты или ламинированные жестяные банки) и хранили при температуре от 2 до $6{ }^{\circ} \mathrm{C}$.

Входными переменными выбраны массы нетто в граммах компонентов рецептуры - базилика и ржаной муки. По результатам предварительных экспериментов были ограничены области факторного пространства и приняты лингвистические термы для всех переменных. Составленная матрица эксперимента использовалась для изготовления опытных образцов продукции и формулирования правил (базы данных). Органолептическая оценка всех опытных образцов продукции проводилась путём расширенной дегустации специалистами.

В программе «Fuzzy logic» пакета MatLab смоделирована рецептура продуктов с наивысшей органолептической оценкой. Результаты моделирования в виде поверхности отклика представлены на рис. 3 . 


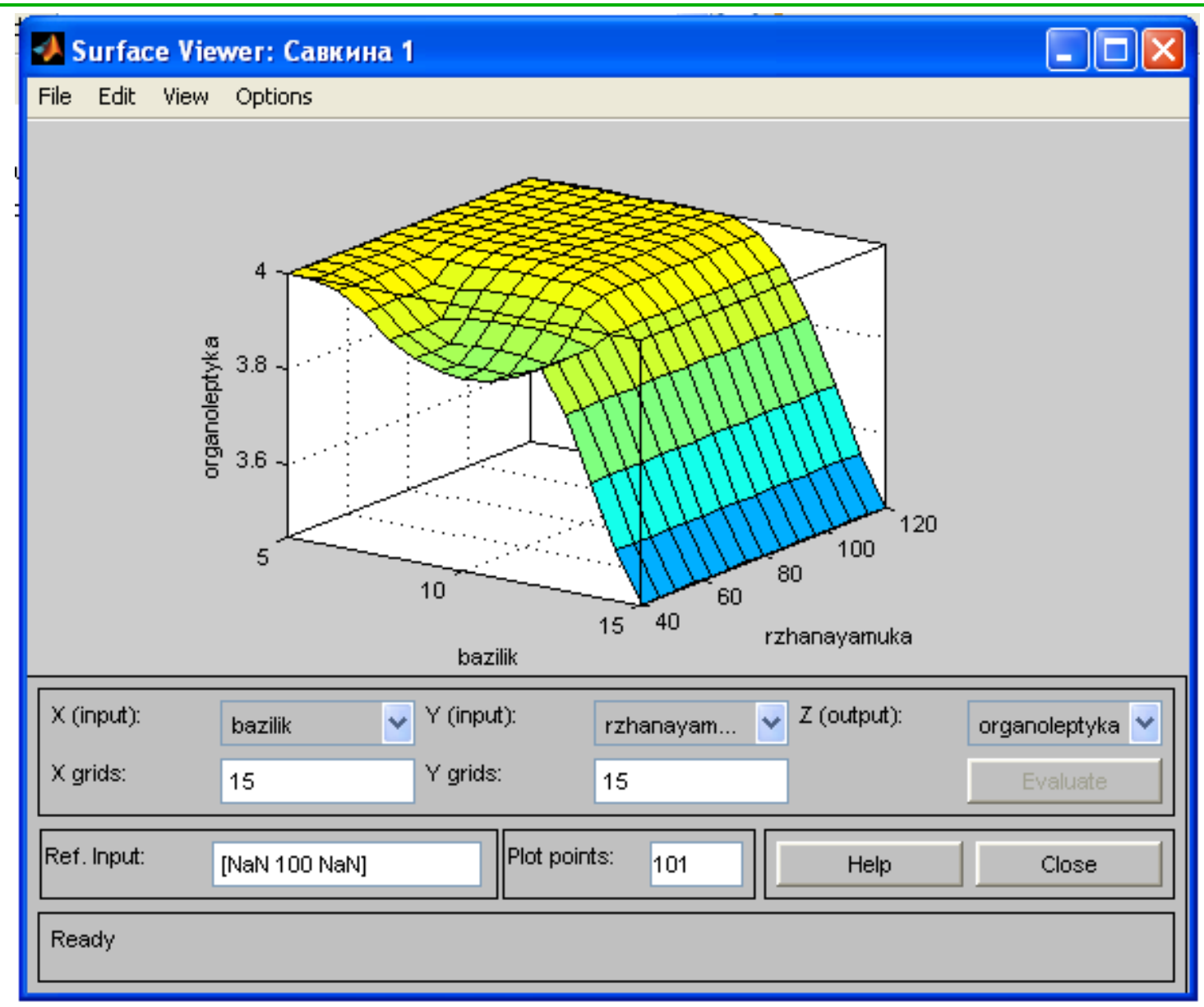

Рис. 3. Поверхность отклика для продукта «Хлебцы итальянские с томатами и базиликом, обогащенные йодом»

Определены оптимальные значения входных переменных для разрабатываемой рецептуры обогащенных хлебцев, которые представлены в таблице 1 .

Таблица 1

Оптимальная рецептура мучного изделия «Хлебцы итальянские с томатами и базиликом, обогащенные йодом»

\begin{tabular}{|c|c|c|}
\hline \multirow{2}{*}{ Компонент } & \multicolumn{2}{|c|}{ Масса, г } \\
\cline { 2 - 3 } & брутто & нетто \\
\hline Томаты & 105 & 100 \\
\hline Мука ржаная & 80 & 80 \\
\hline Мука пшеничная & 50 & 50 \\
\hline Сыр твердый & 43 & 40 \\
\hline Сушеный базилик & 10 & 10 \\
\hline Мед & 10 & 10 \\
\hline Соль & 7 & 7 \\
\hline Водоросли & 0,045 & 0,045 \\
\hline Выход & - & 300 \\
\hline
\end{tabular}


Полученные оптимальные значения факторов проверены экспериментально, показали хорошую сходимость, учтены в конечной рецептуре хлебцев и вошли в проектную техническую документацию ТУ «Хлебцы итальянские с томатами и базиликом, обогащенные йодом». Оптимизацию рецептуры нового рыбного мучного изделия в категории Пироги рыбные «На здоровье», обогащенные хондроитинсульфатом ската звездчатого проводили аналогично описанному выше алгоритму по критерию достижения максимальной органолептической оценки готовым продуктом.

Для изготовления пирогов использовали дрожжевое тесто по классической рецептуре. В середину тестовой заготовки пирога - раскатанное и нарезанное по форме пирога тесто - помещали рыбную начинку, которую готовили следующим образом. Филе трески и мясо бланшированных в воде при температуре от 96 до $98{ }^{\circ} \mathrm{C}$ в течение 1 минуты крыльев ската нарезали на кусочки, соединяли с перцем черным молотым и солью, нарезанным на полукольца репчатым луком, нарезанным тонкими дольками картофелем и слегка размягченным сливочным малом. Далее пирог формуют окончательно по выбранной форме (открытый или закрытый), подвергают расстойке и выпекают при температуре от 200 до $220{ }^{\circ} \mathrm{C}$ в течение примерно 20 минут до полуготовности (в зависимости от массы полуфабриката длительность выпекания может варьироваться). Доведенный до полуготовности пирог охлаждают до температуры не выше $18^{\circ} \mathrm{C}$, упаковывают в потребительскую тару (полипакет термосваренный и картонная коробка) и подвергают шоковой заморозке до температуы в центре пирога не выше минус $18{ }^{\circ} \mathrm{C}$, после чего хранят при той же температуре.

Входными переменными выбраны массовая доля рыбной компоненты в начинке пирога, \% на общую массу начинки и массовая доля ската в рыбной компоненте начинки пирога, \% на общую массу рыбной компоненты. По результатам предварительных экспериментов были ограничены области факторного пространства и приняты лингвистические термы для всех переменных. Составленная матрица эксперимента использовалась для изготовления опытных образцов продукции и формулирования правил (базы данных). Органолептическая оценка всех опытных образцов продукции проводилась путём расширенной дегустации специалистами.

B программе «Fuzzy logic» пакета MatLab смоделирована рецептура продуктов с наивысшей органолептической оценкой. Результаты моделирования в виде поверхности отклика представлены на рис. 4. 
Определены оптимальные значения входных переменных для разрабатываемой рецептуры обогащенных пирогов, которые составили:

- доля рыбной компоненты в начинке пирога - 50 \% на общую массу пирога;

- доля ската в рыбной компоненте начинки пирога - 50 \% на общую массу рыбной компоненты.

Контрольный опыт, выполненный для полученных путем моделирования значений влияющих факторов, показал высокую сходимость модели и реального технологического процесса. Оптимальные значения факторов учтены в конечной рецептуре пирогов и вошли в проектную техническую документацию ТУ «Продукция мучная рыбная из ската звездчатого функционального назначения».

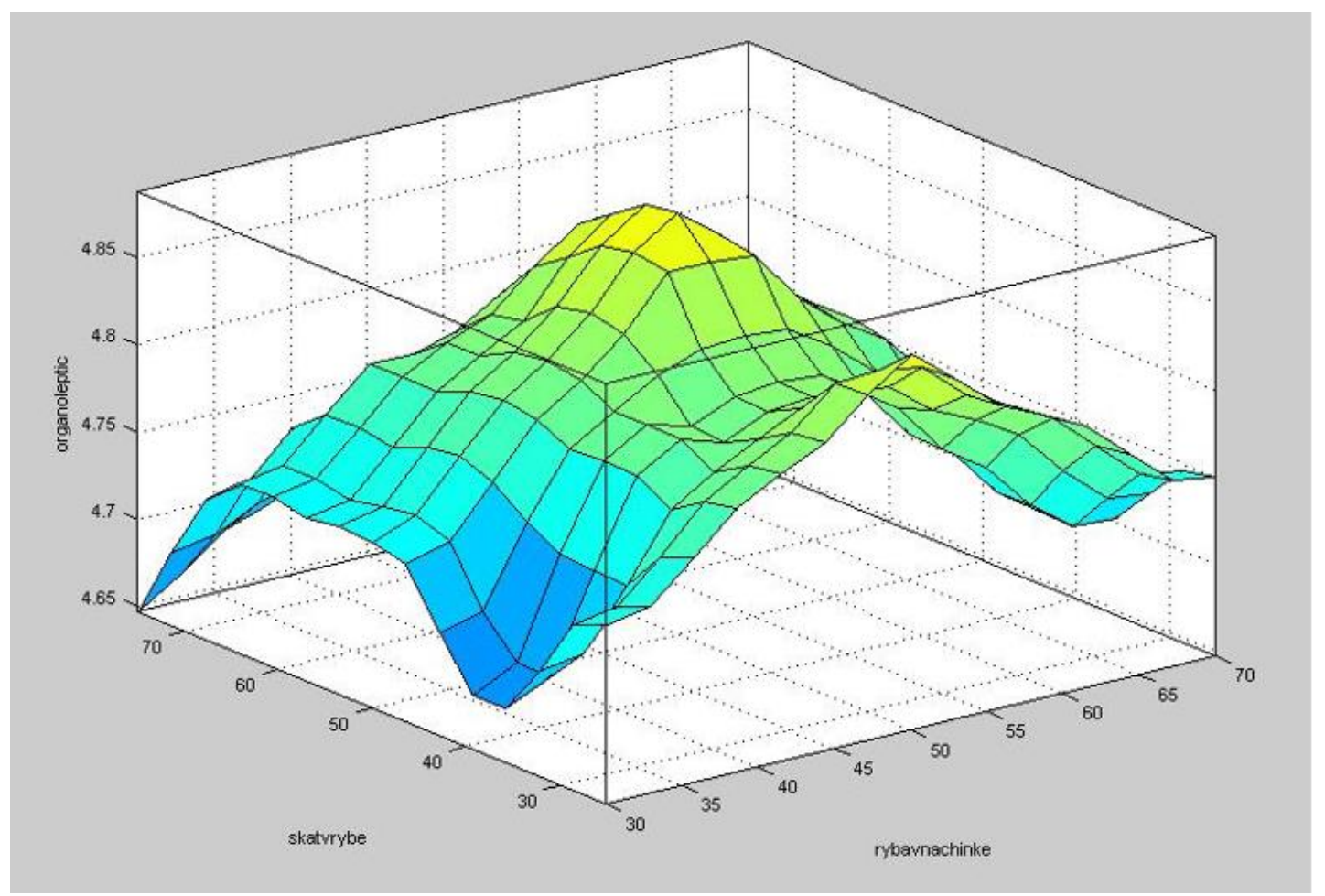

Рис. 4. Поверхность отклика для продукта Пироги рыбыые «На здоровье», обогащенные хондроитинсульфатом ската звездчатого

По итогам проведенных исследований разработаны рецептуры ассортиментной линейки рыбных полифункциональных продуктов, обогащенных ценными пищевыми компонентами и направленных на профилактику йододефицитных состояний и заболеваний опорнодвигательного аппарата человека. 


\section{Список литературы}

1. Попов В.Г. Разработка рецептуры комплексной пищевой физиологически функциональной системы с целью получения специализированных продуктов питания для населения Арктики / В.Г. Попов, Г.Д. Кадочникова, Л.Н. Буракова [и др.] // Ползуновский вестник. - 2019. - №1. - С. 90-95;

2. Потребительский сектор в России 2020. [Электронный ресурс] / Исследовательский центр компании «Делойт» в СНГ. - М.: АО «Делойт и Туш СНГ» - 2020. - Режим доступа: https://www2.deloitte.com/ru/ru/pages/consumerbusiness/articles/2020/potrebitelskiy-sektor-v-rossii-2020.html. (дата обращения: 05.09.2021);

3. Савкина К.Н. Обоснование инновационных пищевых технологий с использованием марикультуры - водорослей Laminaria saccharina / К.Н. Савкина, Р.А. Свистов, Е.А. Новожилова [и др.] // Известия высших учебных заведений. Арктический регион. - 2017. - №1 - С. 78-86. 